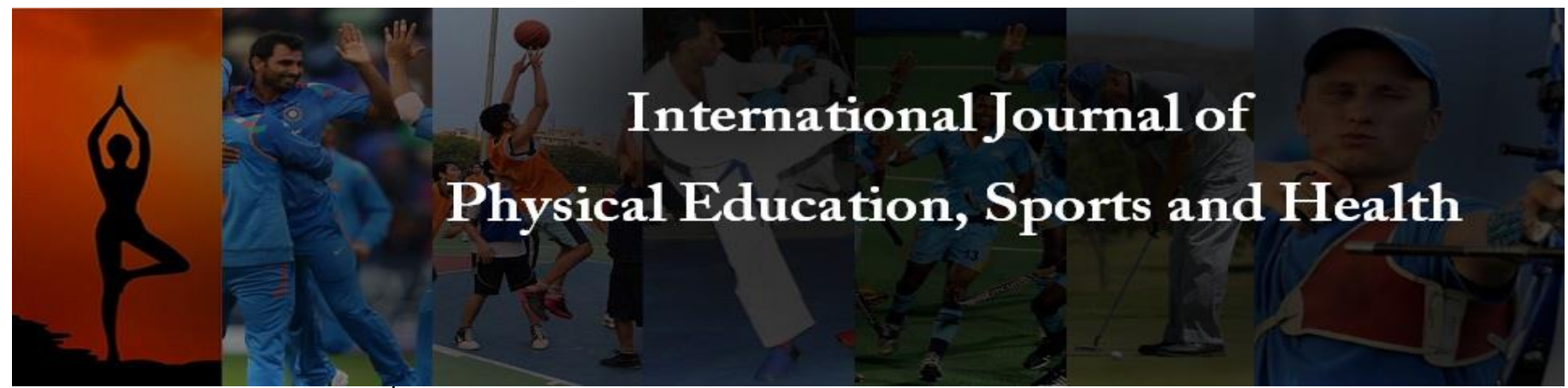

P-ISSN: 2394-1685

E-ISSN: 2394-1693

Impact Factor (ISRA): 5.38

IJPESH 2021; 8(3): XX-XX

(C) 2021 IJPESH

www.kheljournal.com

Received: 16-03-2021

Accepted: 25-04-2021

\section{Anoop Joy}

MPT Scholar, Department of Physiotherapy, Rajiv Gandhi University of Health Sciences, Bangalore, Karnataka, India

\section{Ludhiya Baby}

MPT Scholar, Department of Physiotherapy, Rajiv Gandhi University of Health Sciences, Bangalore, Karnataka, India

\section{Ranjith KV}

Lecturer, Department of

Physiotherapy, Rajiv Gandhi University of Health Sciences, Bangalore, Karnataka, India
Corresponding Author: Ludhiya Baby MPT Scholar, Department of Physiotherapy, Rajiv Gandhi University of Health Sciences, Bangalore, Karnataka, India

\section{Relationship of trunk extensor endurance on dynamic postural control and functional performance in non- specific low back pain}

\author{
Anoop Joy, Ludhiya Baby and Ranjith KV
}

DOI: https://doi.org/10.22271/kheljournal.2021.v8.i3g.2121

\begin{abstract}
Background: The evaluation of causes and consequences of non-specific low back pain along with related symptoms are critical in terms of planning the treatments of patients. Muscular imbalance can cause postural impairment and reduced functional performance in individuals with low back pain. Therefore, determining the role of trunk muscular endurance in individuals with non-specific low back pain and its reflections on dynamic postural control and functional performance are very important for both patients and physiotherapists in terms of establishing an effective treatment program.

Methodology: 39 participants with non-specific LBP aged between 18-50 years were included in this study. Biering-Sorensen test, Y-balance test and 5 min walk test were the outcome measures used to evaluate trunk extensor endurance, dynamic postural control and functional performance.

Result: Using Karl Pearson's Correlation coefficient, strong positive correlation was observed between trunk extensor endurance and 5-minute walk test, and between trunk extensor endurance and Y-balance test, which was found to be highly statistically significant.

Conclusion: This study concludes that there is a strong positive correlation exist between trunk extensor endurance and dynamic postural control, and also between trunk extensor endurance and functional performance in patients with non-specific low back pain.
\end{abstract}

Keywords: low back pain, balance, physical performance, muscular imbalance, endurance, postural instability

\section{Introduction}

Low back pain (LBP) is a very common complaint that can be observed throughout the world in all age groups. Several studies have shown that, occurrence of low back pain in general population and professionals could be due to various work-related musculoskeletal strain, wrong work station and posture, inappropriate lifting techniques etc ${ }^{[1]}$. Studies shows that, lifetime prevalence of low back pain is reported to be as high as $84 \%$, and also suggest that the prevalence of chronic low back pain is about $23 \%$, with $11-12 \%$ of the population being disabled by it ${ }^{[2]}$. It is estimated that $85 \%$ of LBP patients in primary care are without a specific medical diagnosis, and are thus classified as nonspecific LBP ${ }^{[3,4]}$. Non-specific low back pain is defined as low back pain not attributable to a recognisable, known specific pathology like; infection, tumour, osteoporosis, fracture, structural deformity, etc ${ }^{[5]}$.

Patients with LBP often present with trunk muscle imbalances and movement dysfunctions [6]. The ability of the trunk muscles to maintain appropriate levels of activation over long periods of time may be a key factor, to protect the passive structures of the lumbar spine from injury [7]. Most of our daily activities require some muscle endurance. Lack of trunk muscles endurance has been identified as a predictor of earlier occurrence of low back troubles ${ }^{[8]}$. Imbalance in endurance between the trunk flexors and extensors are main reasons for acquiring postural defects, low back pain (LBP), decreased athletic performance and various lumbar spine musculoskeletal injuries ${ }^{[9,10,11]}$. Coordinated activation of the trunk muscles are necessary for maintenance of upright quiet standing posture with minimal postural sway ${ }^{[12]}$.

Similar as trunk endurance, changes in postural stability is also a common factor seen in individuals with LBP. Postural control, can be defined as "the ability to maintain the body's center of gravity within the limits of stability as determined by the base of support" ${ }^{[13]}$. 
Maintenance of static and dynamic postural control is crucial for functional activities ${ }^{[14]}$. Dynamic postural control is an important factor in performing many functional tasks. It refers to maintaining equilibrium during motion or re-establishing equilibrium through rapid and successively changing positions ${ }^{[15]}$. Optimal postural control is an essential factor for safe performance during each and every activities of daily living ${ }^{[12]}$. In non-specific LBP individuals, postural control might be deteriorated, and thus may affect the ability to perform daily activities safely and effectively ${ }^{[14]}$.

It is common that low back pain patients tend to feel unable to carry out their daily activities and often have a strong belief that any functional activity will worsen pain or cause some physical impairment or limitation ${ }^{[16]}$. Studies shows that, there is strong relationship exist between LBP and functional performance [17]. Reduced endurance and increased fatigability of the trunk muscles can also limit functional level in individuals with LBP. Hence it is not possible to conclude specifically whether LBP itself or the reduced trunk muscle endurance is the major cause for reduction of functional performance in patients with non-specific LBP.

Most of the people suffer from LBP at least once in their life, and many of them may experience it more than one period. The evaluation of causes and consequences of non-specific low back pain along with related symptoms are critical in terms of planning the treatments of patients. Therefore, determining the role of trunk muscular endurance in individuals with non-specific low back pain and its reflections on dynamic postural control and functional performance are very important for both patients and physiotherapists in terms of establishing an effective treatment program. So, the aim of this study is to find the relationship of trunk extensor endurance on dynamic postural control and functional performance in patients with non-specific low back pain.

\section{Materials and methods}

The cross sectional study was conducted at tertiary hospital, Mangalore, India. The participants included for the study met the following criteria: low back pain lasting more than 3 months in the past one year; age between 18 - 50 years; and non-radiating back pain confirmed through negative SLR, and Slump test. The exclusion criteria for the present study were malignant tumor, infection, inflammatory disease affecting the spine, recent injury, spinal or lower-limb surgery, spinal fractures, structural deformities such as spondylolisthesis and spondylolysis, pregnancy, any systemic impairments such as cardiovascular disease and respiratory disorder. Outcome measures used for the study were, Biering-Sorensen test to evaluate the trunk extensor endurance, Y-balance test to evaluate the dynamic postural control and 5 min walk test to evaluate functional performance in patients with non-specific low back pain.

Based on a study conducted by Soltandoost Nari SM et al., assuming $\mathrm{r}=0.3$ with $95 \%$ confidence interval, using the formula $\left(Z_{1-\alpha / 2}\right)^{2} \times\left(1-r^{2} x y\right)$ divided by $r^{2} x y$, the sample size estimated for the study is 38.8 approximately equal to 39 . Approval was obtained from Institution Ethical Committee (IEC) and informed written consent was obtained from all the participants before the study begins.

\subsection{Procedure}

Standard instructions were given for all the participants on estimation of trunk extensor endurance, dynamic postural control and functional performance using Biering-Sorensen test, Y-balance test and $5 \mathrm{~min}$ walk test. Participants were given 5-minute rest period after performing each outcome measure in order to avoid fatigue.

\subsubsection{Biering-Sorenson test}

This test was used to determine the endurance of trunk extensors. It is a reliable tool for testing in both asymptomatic (ICC, 0.83) and symptomatic participants (ICC, 0.88). In the evaluation of dynamic muscular endurance, the individual was laid face down, with his/her anterior superior iliac spine (ASIS) in line with the edge of a couch. The lower body was stabilized on the couch using straps at the level of lower thighs and legs; while the upper body was not supported by the surface of the couch. A chair was placed in front of the participant for supporting upper body. Participants were asked to perform trunk extension, with the arms across the chest. The time in which proper trunk extension was maintained was recorded in seconds. The patients informed that the maximum time that they could hold were the evaluation criteria ${ }^{[18]}$.

\subsubsection{Y-balance test}

Y-balance test was used to measure dynamic balance in the study participants. It is a reliable and valid assessment tool $(\alpha=0.86-0.95)$. The test was performed with the participant standing at the center of the platform with 3 tape measures attached to the floor; one in the anterior direction and others positioned $135^{\circ}$ posteromedial and posterolateral from the anterior tape. The participants performed the single-leg stance test while extending the other leg as far as possible with the reach directions (anterior, posteromedial, \& posterolateral). When the reaching foot touched the furthest point possible, the participant returned back to the central point in bilateral stance position. The examiner measured the distance from the center of the grid to the touch point. Reach distance was then normalized by dividing it by the participant's limb length measured from the anterior superior iliac spine to the medial malleolus tip in lie-down position and subsequently multiplying it by $100^{[19]}$.

\subsubsection{5-minute walk test}

This is a simple clinical measure to assess functional performance in patients with LBP. The examiner had marked a 20-meter hallway in an even surface. Each participant was instructed to perform the test by walked up and down the 20meter hallway from the starting point for 5 minutes at their self-paced walking speed. The digital stopwatch was used to measure the time. The investigator counted the laps covered by the individual during $5 \mathrm{~min}$ of walking, to calculate the distance covered by the participant during the task ${ }^{[20]}$.

\subsection{Statistical analysis}

Demographic characteristics of the participants including age, height, weight and BMI were analysed by descriptive statistics. Karl Pearson's correlation coefficient was used to find the relationship of trunk extensor endurance on dynamic postural control and functional performance in non-specific LBP. A statistical package SPSS ver.20.0 was used for analysis and 'p' value $\leq 0.05$ was considered as significant.

\section{Results}

Among 39 participants with age 18-50 years, the Mean and standard deviation of age, height and weight were $35.78 \pm 2.2$ years, $162.65 \pm 8.3 \mathrm{~cm}$ and $61.43 \pm 8.8 \mathrm{~kg}$ respectively. (Table 1) Using Karl Pearson's Correlation coefficient, it was observed that strong positive correlation exists between trunk extensor endurance and 5-minute walk test $(r=0.834)$, trunk 
extensor endurance and Y-balance test using right lower limb $(\mathrm{r}=0.945)$, trunk extensor endurance and $\mathrm{Y}$-balance test using left lower limb $(r=0.909)$, respectively. This result was found to be highly statistically significant $(p<0.001)$. (Table 2)

Table 1: Demographic characteristics of the participants

\begin{tabular}{|c|c|c|}
\hline Variables & Mean & SD \\
\hline Age $($ years $)$ & 35.78 & 2.2 \\
\hline Height $(\mathrm{cm})$ & 162.65 & 8.3 \\
\hline Weight $(\mathrm{kg})$ & 61.43 & 8.8 \\
\hline
\end{tabular}

Table 2: Correlation coefficient between Trunk extensors endurance (TEE) with 5- minute walk test (5-MWT), Right Y balance test (Right-YBT) and Left Y balance test (Left- YBT)

\begin{tabular}{|c|c|c|c|c|}
\hline \multicolumn{2}{|c|}{} & 5-MWT & Right-YBT & Left- YBT \\
\hline \multirow{4}{*}{ TEE } & Pearson Correlation & $.834^{* *}$ & $.945^{* *}$ & $.909^{* *}$ \\
& Sig. (2-tailed) & .000 & .000 & .000 \\
& $\mathrm{~N}$ & 39 & 39 & 39 \\
\hline
\end{tabular}

**Correlation is significant at the 0.01 level (2-tailed)

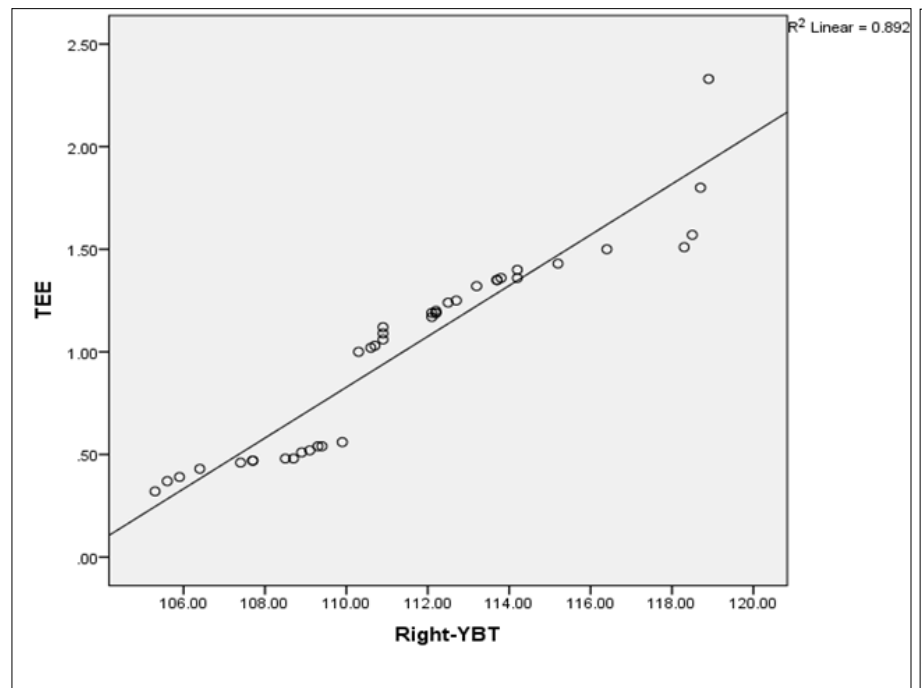

Fig 2: Scattered diagram of correlation between TEE and Right-YBT

\section{Discussion}

A cross sectional study was designed to find the relationship of trunk extensor endurance on dynamic postural control and functional performance in patients with non-specific low back pain. It is a well-known fact that LBP is a most common condition which has high prevalence in the worldwide. Studies shows that among LBP cases most of them were categorized as non-specific low back pain due to their nonidentifiable cause ${ }^{[21]}$. Reduced endurance or weakness of surrounding supporting structures of low back region may be a reason for altered posture, instability and may result in LBP. Lewis $\mathrm{F}$ et al. reported that most of the LBP patients demonstrated reduced trunk extensor endurance and thereby cause postural imbalance [22]. This may lead to reduced functional performance in patients with non-specific LBP. So, this study was sought on hypothesis that, there is some relationship exist between trunk extensor endurance and dynamic postural control and functional performance in patients with non-specific LBP.

39 participants with non-specific LBP aged between 18-50 years were included in this study. Trunk extensor endurance, dynamic postural control and functional performance of all the participants were measured using Biering-Sorensen test, Y-balance test and 5 min walk test. Karl Pearson's correlation

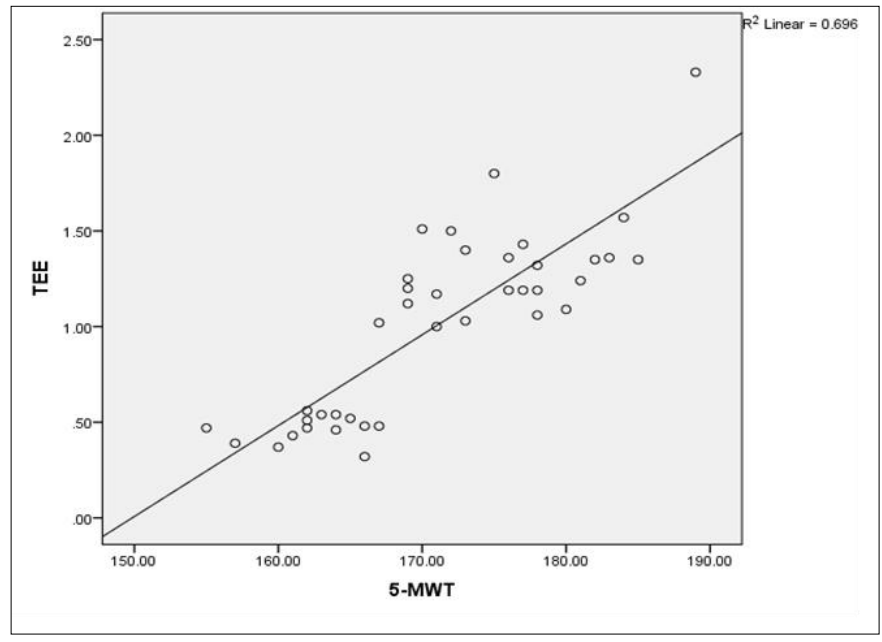

Fig 1: Scattered diagram of correlation between TEE and 5-MWT

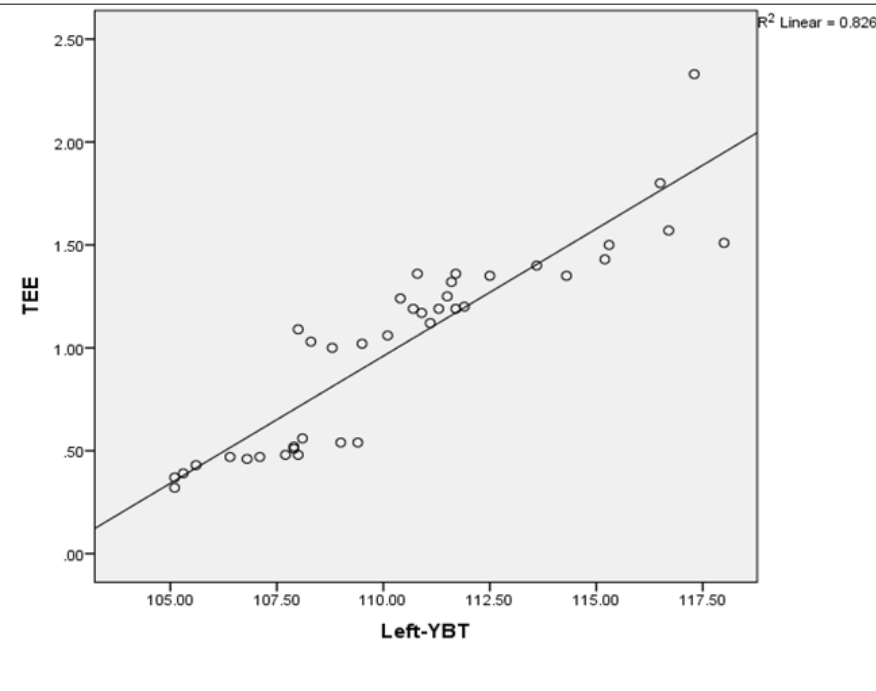

Fig 3: Scattered diagram of correlation between TEE and Left-YBT

coefficient was used to analyse the result obtained using these outcome measures.

While analysing the relationship between trunk extensor endurance and functional performance, it was observed that strong positive correlation exists between trunk extensor endurance and 5-minute walk test. This indicate that, when the trunk extensor endurance gets reduced, functional performance will also get reduced in patients with nonspecific LBP. In accordance with the result of our study, Soltandoost Nari SM and Shamsoddini A. in their study conducted on military personnel with chronic low back pain reported that positive correlation exists between trunk muscle endurance and functional capacity in individuals with chronic LBP ${ }^{[19]}$. This may be due to the reason; trunk muscles play an important role in the functional activity of each individuals. If the trunk extensor endurance gets reduced, it can cause muscle imbalance and can negatively affect the ability of an individual to bear load on their back during standing, walking and in each functional tasks. In case of individuals with nonspecific LBP, this muscle imbalance due to reduced trunk extensor endurance can increase the stress and strain in their back which may limit the individuals from their functional performance.

While correlating trunk extensor endurance with dynamic 
postural control, our study shows strong positive correlation between trunk extensor endurance and Y- balance test (right and left). Result of our study indicate that while trunk extensor endurance gets reduced in patients with non-specific LBP, their dynamic postural control will also get reduced. Thakkar HH et al. suggests that reduced back muscle strength and coordination contributes to decrease postural control and balance in patients with chronic low back pain ${ }^{[23]}$. Supporting the result of our study, Bezgin $\mathrm{S}$ et al. Reported significant relationship between trunk extensor endurance and functional balance in participants with chronic low back pain ${ }^{[18]}$. In contrast to this result, Behennah $\mathrm{J}$ et al., reported there were no significant correlations between trunk extensor endurance and dynamic balance in either the participants with chronic low back pain or the asymptomatic participants ${ }^{[24]}$. High level of muscle endurance is required to control an erect posture and muscular imbalance can cause postural instability. Reduced trunk extensor endurance can cause muscular imbalance in patients with non-specific low back pain. This can cause postural instability and difficulty in controlling erect posture during their activities of daily living.

Thus, trunk extensor endurance act as a key factor in both dynamic postural balance and functional performance in patients with non-specific LBP. Improving trunk extensor endurance will be a right option to increase dynamic balance and functional performance in individuals with LBP. Therefore, evaluation of trunk extensor endurance should be taken into prior, to provide an effective treatment to patients with non-specific LBP.

\subsection{Limitation}

In the present study only the trunk extensor endurance relationship with dynamic postural control and functional performance was assessed. Relationship of both trunk extensor and flexor endurance could provide a better idea on postural imbalance and functional performance in patients with non-specific LBP. The scope for future studies to assess the trunk flexor and extensor endurance relationship on dynamic postural control and functional performance in nonspecific LBP with a larger sample size.

\section{Conclusion}

This study concludes that there is a strong positive correlation exist between trunk extensor endurance and dynamic postural control, and also between trunk extensor endurance and functional performance in patients with non-specific low back pain.

\section{Acknowledgment}

We express our sincere gratitude to all the participants who had participated in this study. We acknowledge the guidance and support of statistician in our study.

\section{References}

1. Nyland LJ, Grimmer KA. Is undergraduate physiotherapy study a risk factor for low back pain? A prevalence study of LBP in physiotherapy students. BMC Musculoskelet Disord 2003;4:22.

2. Airaksinen O, Brox JI, Cedraschi C, Hildebrandt J, Klaber-Moffett J, Kovacs F et al. European guidelines for the management of chronic nonspecific low back pain. Eur Spine J 2006;15(Suppl 2):S192-300.

3. Davarian S, Maroufi N, Ebrahimi I, Farahmand F, Parnianpour M. Trunk muscles strength and endurance in chronic low back pain patients with and without clinical instability. J Back Musculoskelet Rehabil 2012;25(2):123-9.

4. Petersen T, Laslett M, Thorsen H, Manniche C, Ekdahl $\mathrm{C}$, Jacobsen S. Diagnostic classification of non-specific low back pain. A new system integrating patho-anatomic and clinical categories. Physiother Theory Pract 2003;19(4):213-37.

5. Louw QA, Morris LD, Grimmer-Somers K. The prevalence of low back pain in Africa: a systematic review. BMC Musculoskelet Disord 2007;8:105.

6. Comerford MJ, Mottram SL. Movement and stability dysfunction-contemporary developments. Man Ther 2001;6(1):15-26.

7. Evans K, Refshauge KM, Adams R. Trunk muscle endurance tests: reliability, and gender differences in athletes. J Sci Med Sport 2007;10(6):447-55.

8. Naveen G, Manoj M, Kulandaivelan S. Correlation of trunk extensors endurance with pain and disability in patients with non-radiating chronic low back pain. Int $\mathbf{J}$ Physiother Res 2014;2(1):329-33.

9. Mahmoud EW, Salem EE, El-Hadidy EI. Correlation between Anthropometric Measurements and Trunk Muscles Endurance for Normal Young Girls. Trends Appl Sci Res) 2015;10(2):117-24.

10. McIntosh G, Wilson L, Affieck M, Hall H. Trunk and lower extremity muscle endurance: normative data for adults. J Rehabil Outcome Meas 1998;2(4):20-39.

11. Selvaganapathy K, Rajappan R, Balachanthran CM. The relationship between trunk muscles endurance and normal BMI among university students with sedentary lifestyle. Int J Physiother 2017;4(6):358-62.

12. Durmus D, Akyol Y, Alayli G, Tander B, Zahiroglu Y, Canturk F. Effects of electrical stimulation program on trunk muscle strength, functional capacity, quality of life, and depression in the patients with low back pain: a randomized controlled trial. Rheumatol Int 2009;29(8):947-54.

13. Svensson HO, Andersson GB, Johansson S, Wilhelmsson C, Vedin A. A retrospective study of low-back pain in 38- to 64-year-old women. Frequency of occurrence and impact on medical services. Spine (Phila $\mathrm{Pa}$ 1976). 1988;13(5):548-52.

14. Alsufiany MB, Lohman EB, Daher NS, Gang GR, Shallan AI, Jaber HM. Non-specific chronic low back pain and physical activity: A comparison of postural control and hip muscle isometric strength: A crosssectional study. Medicine 2020;99(5):1-10.

15. Krishna HS, Shetty S, Raj AS. Relationship between core endurance and dynamic balance in college level football players: A pilot study. Int J Phys Educ Sports Health 2020;7(5):149-153.

16. Fracaro GD, Bertor WR, Silva LI, Brandl L, Zanini GM, Zilio $\mathrm{M}$ et al. Comparison of psycho-social and functional performance variables in a group of chronic low back pain patients. Revista Dor 2013;14:119-23.

17. Heneweer H, Staes F, Aufdemkampe G, van Rijn M, Vanhees L. Physical activity and low back pain: A systematic review of recent literature. Eur Spine J 2011;20(6):826-45.

18. Bezgin S, Aydoğan S, Sertel M, Vergili Ö, Kocaman AA, Oral MA et al. The relationship between balance, trunk muscular endurance, and functional level in individuals with chronic low back pain. Ann. Med. Res 2020;27(2):582-7.

19. Soltandoost Nari SM, Shamsoddini A. Relationships 
between Functional Movement Screen and Pain, Dynamic Balance, and Trunk Muscle Endurance in Military Personnel with Non-specific Chronic Low Back Pain. Physical Treatments 2020;10(4):221-30.

20. Waddell G. The back pain revolution. New York, Churchill, Livingstone 1998.

21. Hlaing SS, Puntumetakul R, Wanpen S, Boucaut R. Balance Control in Patients with Subacute Non-Specific Low Back Pain, with and without Lumbar Instability: A Cross-Sectional Study. J Pain Res 2020;13:795-803.

22. Lewis F, Wood W, Olivier B. The association between trunk muscle endurance and lumbo-pelvic stability in adolescent low back pain: A cross sectional study. S Afr J Physiother 2013;69(1):17-21.

23. Thakkar HH, Kumar S. Static and dynamic postural stability in subjects with and without chronic low back pain. Int J Res Med Sci 2015;3(9):2405-2409.

24. Behennah J, Conway R, Fisher J, Osborne N, Steele J. The relationship between balance performance, lumbar extension strength, trunk extension endurance, and pain in participants with chronic low back pain, and those without. Clin Biomech 2018;53:22-30. 